time-intervals, snippets were cut off and supercontracted.

The results are shown in Figs. 1 and 2. It is obvious that reduction of $3 \mathrm{hr}$. is sufficient in the case of Merino wool to break the fibre down to such an extent that partial solution takes place in the contractant. This partial solution could, in fact, be observed under the microscope, particularly at the snippet ends. Due to this partial solution, progressive elongation takes place after the initial rapid contraction. This contraction, which gave values in good agreement with normal equilibrium contraction, was in certain cases so rapid that it could not be photographed effectively at the one-second exposure-time used, and, consequently, no contraction values are shown in the figures. However, as the fibre is progressively exposed to atmospheric oxidation, the extent of partial solution decreases until final contraction values are eventually obtained corresponding to positive contraction. This is probably indicative of the restoration, through atmospheric oxidation, of the disulphide network which is mainly responsible for keratin stability. It would, therefore, be inadvisable to perform supercontraction studies on reduced wool unless precautions are taken to prevent reformation of cross-linkages.

O. A. Swanepoet

South African Wool Textile Research Institute, Grahamstown, South Africa.

1 Haly and Feughelman, Text. Res. J., 30, 365 (1960).

2 O'Donnell, Text. Res. $J, 24,1058$ (1954).

${ }^{3}$ Schöberl, Angew. Chem., 70, 646 (1958).

4 Haly and Griffth, Text. Res. J., 28, 32 (1958).

s Zahn and Traumann, Melliand Textil Berichte, 35, 1069 (1954).

\section{Ultrasonic Detection of Choledocholithiasis}

Present-DaY methods of detecting gall-stones in the common bile duct at operation are not wholly satisfactory. Stones may be missed in spite of careful palpation, cholangiography and direct exploration of the common bile duct. An attempt has been made to use pulsed ultrasound at the time of operation as an adjunct to their detection.

The apparatus used was a Kelvin and Hughes Mark V F flaw detector which is used industrially for the detection of flaws in homogeneous structures such as steel. The detecting probe contains both transmitting and receiving transducers and operates at $2 \cdot 5 \mathrm{Mc}$ /sec. The transducer emits pulsed ultrasound which is transmitted through a liquid or solid medium with attenuation and is reflected wholly or in part from the surface of any obstruction, the acoustic impedance of which differs sufficiently from that of the medium. The reflexion or echo is picked up by the receiving transducer and the electrical signal generated is amplified and displayed on a cathode ray oscilloscope with a linear time base to give a rough depth calibration (referred to as $A$-scope presentation).

Gall-stones of differing composition (cholesterol, pigment and mixed) and varying in size from 3 to $30 \mathrm{~mm}$. were examined in a tank of saline and definite echoes were obtained from them. They were located by adjusting the position of the transducer head. The optimum range was $3-10 \mathrm{~cm}$. Very slight movement of the transducer produced a marked difference in the size of the echo.

Similar findings were obtained from gall-stones in fresh post-mortem bile ducts and in gall-bladders removed at operation. There were, however, two main differences; the minimum size of gall-stone detectable in bile ducts was $6 \mathrm{~mm}$., and detection. proved difficult when the walls of the biliary ducts were grossly thickened by disease. Similar results were obtained when gall-stones in the common bile duct were detected at operation. To provide a liquid medium between the probe and the common bile duct, about $0.5 \mathrm{l}$. of sterile water was poured into the upper abdomen. The probe was enclosed in a sterile latex sleeve.

Although it is possible with $A$-scope presentation to use ultrasound to detect gall-stones in the common bile duct at operation, the technical difficulties are considerable ${ }^{1}$. It would seem that further research using $B$-scope with plan position indicator ${ }^{2}$, which gives a two-dimensional picture, may have some. thing more reliable to offer the surgeon.

We wish to express our gratitude to Prof. W. R. Spurrell, Prof. C. B. Allsopp, Prof. R. Warwick and Prof. G. W. Taylor in whose departments at Guy's and St. Bartholomew's Hospitals the work was carried out. We would also like to acknowledge a grant for this work from the Clinical Research Committee, Guy's Hospital, and to thank Messrs. Kelvin and Hughes for the generous loan of the ultrasonic flaw detector, and the London Rubber Co. for providing the latex sleeves.

$$
\begin{aligned}
& \text { Physics Department, } \\
& \text { Guy's Hospital, } \\
& \text { London, S.E.1. }
\end{aligned}
$$

MaRJorie J. HILL

Surgical Professorial Unit, St. Bartholomew's Hospital, London, E.C.1.

${ }^{1}$ Hill, M. J., and McColl, I., Med. Biol., Ill., 11, 27 (1961). ¿ Donald, I., MacVicar, J., and Brown, T. G., Lancet, i, 1188 (1958).

\section{BIOCHEMISTRY}

\section{Introduction of the I6 $\alpha$-Hydroxyl Group into Cstrogens by Streptomycetes}

PAPERs concerned with the microbiological transformation of steroids have appeared frequently in the past seven years; however, no examples of the hydroxylation of steroids with a benzenoid $A$ ring have been observed. We have been able to introduce a hydroxyl group into the $16 \alpha$-position of cestrone and œestradiol with two strains of Streptomyces halstedii ( $A T C C$ 13,499 and NRRL B-2138) and Streptomyces mediocidicus ATCO 13,278.

The cultures were grown for two days in shake flasks at $28^{\circ}$ on a medium which contained yeast extract, cerelose, ' $\mathrm{NZ}$ amine' type $B$ (an enzymatic digest of casein purchased from Sheffield Chemical, Norwich, N.Y.) and calcium carbonate at an initial $p H$ of $6 \cdot 7$. This growth in $100 \mathrm{ml}$. was used to inoculate 21 , of the same medium contained in a 41 . fermenter. This mixture was incubated at $28^{\circ}$ with stirring at 1,750 r.p.m. and aeration at one volume per volume per minute for $22 \mathrm{hr}$. After this period, $500 \mathrm{mgm}$. of oestrone were added in powdered form. The $p \mathbf{H}$ of the broth was approximately $6 \cdot 5$. The fermentation was continued under the same conditions, for $24 \mathrm{hr}$. At this time, the whole broth was extracted twice with an equal volume of chloro. form. The concentrated extract was qualitatively 